Edgar Straehle. Licenciado en Filosofía, en Historia y en Antropología. Docente e investigador en la Universitat de Barcelona. Miembro del Seminario de "Filosofia i Gènere", del Seminario de Filosofía Política de la Universitat de Barcelona y del GAPP (Grup Arendtià de Pensament i Política). Autor de diversas publicaciones en torno al pensamiento político, al feminismo y a los nuevos movimientos políticos. Sus principales temas de investigación son acerca del concepto de autoridad y del pensamiento de Hannah Arendt.

Contacto: edgarstraehle@gmail.com 


\title{
SENDEROS NUEVOS DEL CAPITAL: TRABAJO, CONSUMO Y PRODUCCIÓN DE SUBJETIVIDAD
}

\author{
Edgar Straehle
}

Universitat de Barcelona

\section{NEW CAPITAL PATHS: LABOUR, CONSUMPTION AND SUBJECTIVITY PRODUCTION}

DOI: $10.17450 / 150205$

Fecha de recepción 18 de septiembre 2015; fecha de aceptación 27 de octubre 2015. El presente artículo se ha realizado en el marco del proyecto de investigación "Filósofas del siglo XX: Maestros vínculos y divergencias" y del GRC "Creació i pensament de les dones", Universitat de Barcelona ${ }^{1}$.

\section{Resumen}

En este artículo se exponen tres figuras del capital: primero, la delineada por Schumpeter, donde el capitalismo se renueva gracias a la destrucción creativa; luego la de Boltanski y Chiapello, donde la lógica de su regeneración no suprime el afuera, sino que

1. La investigación ha podido llevarse a cabo gracias al apoyo de la Secretaria d'Universitats i Recerca del Departament d'Economia i Coneixement de la Generalitat de Catalunya (2013FI_B 01083). Que conste mi agradecimiento a Ekhi Lopetegui, Ana Lanfranconi y María Luisa Vieta por sus observaciones. 
lo domestica y resignifica; finalmente, una tercera donde ese afuera no es propiamente integrado o neutralizado sino captado como productividad o capital. De allí que se impulse una producción de subjetividad como el capital humano, que no sólo coloniza las diferentes esferas de la existencia sino que también, bajo la figura del prosumidor, convierte el consumo en producción.

\section{Palabras clave}

Capital humano, prosumidor, Schumpeter, Boltanski y Chiapello, capitalismo cognitivo.

\section{Abstract}

This article outlines three faces of capital: first, the description of Schumpeter and his theory of creative destruction; second, the diagnosis of Boltanski and Chiapello, where the regeneration of capitalism does not stand on the suppression of this outside but on its domestication and resignification. Finally, the third shape, in which this outside is not envisaged as an ended reality but captured as a productivity or capital. Therefore, this kind of capitalism fosters a production of subjectivity as the human capital, which not only pervades the different fields of existence but as well, under the figure of the prosumer, transforms consummation into production.

\section{Keywords}

Human capital, prosumer, Schumpeter, Boltanski and Chiapello, Cognitive Capitalism.

Economics are the method, the object is to change the soul

Margaret Thatcher

Hoy, la vida es el campo de batalla Santiago López Petit. La movilización global

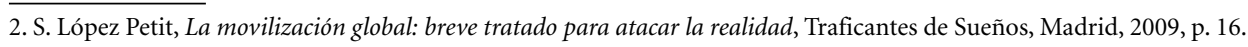




\section{Tres figuras del capital}

En 1942 Joseph Alois Schumpeter escribió Capitalismo, socialismo y democracia. El aspecto más conocido del libro hace alusión a la destrucción creadora, uno de los escasos puntos de la obra que todavía se mencionan con cierta profusión en la actualidad. Schumpeter acuñó esta expresión, que en su opinión constituía el rasgo esencial del capitalismo, con el propósito de reflejar cómo este sistema económico, lejos de ser estacionario o armónico, puede ser aprehendido en tanto que un proceso de transformación acelerado y en desequilibrio que se halla gobernado por la enérgica irrupción de lo nuevo, donde aquello que emerge reemplaza y engulle a lo viejo. La novedad adopta así el rostro de una destrucción, aquella que para surgir e imponerse precisa la eliminación de lo previo, con lo que el capitalismo se destapa como una pugna incesante entre sendos polos.

El economista austríaco también apuntó otra cuestión, conectada con la anterior, que ha recibido menor atención. De acuerdo con su diagnóstico, el capitalismo no era un régimen económico propio, autónomo o autosuficiente. Tampoco lo consideraba como una auténtica o acabada forma social, sino como el último escalón en el dilatado y paulatino proceso de descomposición del feudalismo. Para Schumpeter, el capitalismo no podía ser el fin de la historia y constituía una etapa forzosamente transicional, pues "al romper el marco precapitalista de la sociedad el capitalismo rompió, por tanto, no sólo las barreras que impedían su progreso, sino también los arbotantes que impedían su colapso" ${ }^{3}$ Envuelto en sus contradicciones, estaría fatalmente condenado a su colapso, a su autofagocitación, pues la actitud crítica que había generado, incentivado y propagado, que había servido para derrocar la autoridad bajo la cual se asentaban las instituciones feudales, se volvería con posterioridad y de manera ineluctable en contra de las suyas propias, abalanzándose contra la propiedad privada y socavando el sistema de valores burgueses. Para Schumpeter, el mismo éxito del capitalismo era aquello que anunciaba y lo conducía a su ocaso y extinción. Todo progreso no lo era más que hacia su fin.

Como se sabe, Schumpeter profetizó con pesar que el capitalismo desembocaría en la emergencia del socialismo. Lo que importa, empero, no es valorar este controvertido

\footnotetext{
3. J. A. Schumpeter, Capitalismo, socialismo y democracia, Folio, Barcelona, 1996, vol. I, p. 189. Más adelante, acercándose a su modo a las tesis de Rosa Luxemburg y David Harvey, afirma en el mismo sentido: "El orden capitalista no sólo descansa sobre pilares hechos de material extracapitalista, sino que también extrae su energía de normas de conducta extracapitalistas, a las que al mismo tiempo está abocado a destruir” (p. 217). Así pues, estos componentes extracapitalistas no serían solamente el origen sino también la raison d'être del capitalismo.
} 
pronóstico sino señalar que el economista austríaco fue uno de los primeros en observar, además de los componentes dinámicos y rupturistas ínsitos a la lógica del capitalismo, donde toda evolución era sinónimo de destrucción y disolución, que esta forma histórica se desarrollaba como una contienda constante entre su adentro y su afuera; esto es, entre unos actores e instituciones guiados por una racionalidad económica y otros que desde diferentes ángulos y posiciones se le contrapondrían. El capitalismo, por lo tanto, aparecería como el constante y pertinaz empeño de colonizar los ámbitos y márgenes extracapitalistas, aquellos espacios que ofrecen resistencia a su empuje y a su manera de concebir el mundo. Con el tiempo eso incluiría, asimismo, los valores burgueses, el respeto a la autoridad o el viejo sentido de la disciplina, centrales según su opinión para la supervivencia del capitalismo.

Hace menos años, en 1999, Luc Boltanski y Ève Chiapello publicaron El nuevo espíritu del capitalismo. Sendos autores desgranaron en esta portentosa obra las oscilaciones padecidas por el capitalismo después de acontecimientos como los acaecidos en Mayo del 68. El capitalismo es entendido aquí bajo el mismo prisma dinámico de Schumpeter, como un proceso en movimiento que no cesa de absorber y devorar elementos exteriores que, apropiados a su manera, le resultan provechosos para perseverar en su salvífica transformación. Ahora bien, esta transformación sufre una modificación esencial: no se hace contra el afuera de Schumpeter sino desde este mismo afuera. La identidad no se contrapone a un exterior absoluto ni se renueva por factores endógenos sino (también) exógenos e incluso hostiles, presuntamente incompatibles. Así pues, el capitalismo no es una forma pura y comparece bajo un aspecto híbrido, con un origen heterogéneo. Uno de los pasajes fundamentales del libro asevera que "para mantener su poder de movilización, el capitalismo debe incorporar recursos que no se encuentran en su interior, acercarse a las creencias que disfrutan, en una época determinada, de un importante poder de persuasión y tomar en consideración las ideologías más importantes - incluidas aquellas que le son hostiles - que se encuentran inscritas en el contexto cultural en el cual se desarrolla".

No se trata, pues, fundamentalmente de una acérrima pugna con lo otro sino de una apropiación selectiva y transfiguradora, que sigue deliberadamente una lógica como la del traduttore traditore, que incorpora los discursos y prácticas de ese afuera que, una vez resignificados y neutralizados, pueden reintegrarse sin problema alguno en su seno. El capitalismo no se contenta con doblegar a sus rivales; además, se apoya en ellos, y los

\footnotetext{
4. L. Boltanski, E. Chiapello, El nuevo espíritu del capitalismo, Akal, Madrid, 2002, p. 61.
} 
necesita, para su regeneración. De este modo, perdura y se expande gracias a un afuera que se le aparece como un suelo nutricio. La lógica no es la del exterminio del otro sino la de su domesticación y patrimonialización. Frente a Schumpeter, la alteridad, lo extracapitalista o lo anticapitalista, no deja de constituir una amenaza, pero también opera como el resorte oportuno para su supervivencia y evolución. Como lacónicamente puntualizaron Boltanski y Chiapello, el capitalismo necesita la ayuda de sus enemigos. ${ }^{5}$

En estos casos se lleva a cabo un proceso que hemos bautizado con el nombre de la lógica del desreconocimiento: se pone en práctica un tipo de reconocimiento parcial e incompleto que en realidad esconde primariamente la voluntad de no reconocer en un sentido verdadero a eso que siente como alteridad. Se trata de un acercamiento hecho a desgana y forzado por las circunstancias, indispensable para la propia supervivencia, que procura vaciar de peligrosidad a aquello que se reconoce. El objetivo estriba en capturar sus elementos afines o integrables y desembarazarse de aquellos peligrosos. La lógica del desreconocimiento se caracteriza por detentar una doble función, una de cariz positivo y otro negativo, que a la hora de la verdad se encuentran inextricablemente unidas: para empezar, se le sustrae a la realidad amenazante su potencial de transformación a cambio de generar un simulacro que pueda ser ufanamente presentado como un avance; para seguir, y por lo anterior, se desarticula o por lo menos mitiga el peligro representado por la amenaza en cuestión. Es decir, se trata de reconocer en la medida en que se desreconoce, en que la asunción de la novedad, exhibida como progreso, se efectúa al precio de desustancializarla, recontextualizarla y resignificarla. En verdad, lo que se reconoce no es más que la misma apropiación.

Se cultiva así una filosofía de la historia donde el capitalismo es situado como el producto resultante de un conglomerado de acontecimientos y movimientos que, pese a haber podido ser explícitamente anticapitalistas, son releídos e incorporados de manera forzada y tergiversada a su relato. Se pone en práctica una teleología del presente que distorsiona y sobredetermina el sentido de los hechos pretéritos, que interviene en el pasado con el objeto de justificar y legitimar el statu quo, para hacerlo pasar como algo natural o benéfico. La historia deviene entonces una de las principales armas ideológicas. ${ }^{6}$

Finalmente, queremos destacar la eclosión de una tercera figura emergente, cada vez más difundida y consolidada, más omnipresente, que en realidad se combina, entremezcla y apoya en las otras dos (las cuales, en cualquier caso, no son del todo excluyentes).

\footnotetext{
5. Ibid., p. 71.

6. Por lo que respecta a las maniobras de releer y resignificar el Mayo del 68, si bien sería fácil enumerar muchos otros acontecimientos, véase K. Ross, Mayo del 68 y sus vidas posteriores: ensayo contra la despolitización de la memoria, Acuarela, Madrid, 2008.
} 
En los últimos tiempos, en especial tras la explosión de las tecnologías de la información y la emergencia de eso que se ha venido a llamar capitalismo cognitivo, ${ }^{7}$ en cuyo seno el trabajo inmaterial cobra un creciente protagonismo, podemos encontrarnos con un rostro cuyo gesto radica en una maniobra de apropiación distinta: no se trata sólo de una multiplicidad de dinámicas rupturistas que liquidan o disuelven el afuera, tampoco de otras que se sirven de la alteridad para reelaborar o reformular la identidad, por cierto en absoluto homogénea, coherente o uniforme; lo que ahora entra en juego, aunque se desarrolla en continuidad de lo anterior, es lo que podemos catalogar como la tentativa de apropiación de la (a la postre imprevisible) capacidad productiva y creativa de los usuarios. Se trata, pues, de la captura no de una realidad acabada, no de algo existente, como en la exposición de Boltanski y Chiapello, sino de una potencialidad que aún no ha cristalizado y que es asumida como una productividad por explotar o capitalizar. No consiste tanto en la apropiación de ese supuesto afuera como de los efectos de las acciones de los individuos. Así pues, no importa tanto lo que uno es como lo que uno puede ser, aquello en lo que uno puede convertirse o puede llegar a hacer con los recursos disponibles. Naturalmente, el objetivo del capital consistirá en tratar de establecer el conjunto de condiciones que fomenten la eclosión de esta potencialidad.

Por ello, esta tercera figura se destapa asimismo como la producción de una nueva forma de subjetividad, y recientemente Dardot y Laval se han referido en este sentido a la emergencia de un neosujeto. ${ }^{8}$ La flexibilidad del capitalismo contemporáneo requiere la correspondiente flexibilización de sus trabajadores, su capacidad de autotransformación. Se asume que la realidad no es ni sólida ni rígida ni estable, que moramos en un hábitat de persistente e incluso acelerada transformación. Ahora bien, todo aquello que impera en el presente corre el riesgo de estar condenado a quedar desfasado u obsoleto en poco tiempo. El peligro de quedarse fuera o rezagado es constante e inerradicable, y uno siente la perenne necesidad de actualizarse y ponerse mínimamente al día. Por esa razón, la adaptación no lo es a una realidad fija sino a un proceso en perpetuo movimiento. El capitalismo se reinventa sin cesar y demanda la consiguiente reinvención (continuada) de sus trabajadores. Aquí yace la cuestión clave: el sujeto que se produce debe ser un sujeto asimismo productor, tener la capacidad de operar reflexivamente sobre sí mismo y autoconstituirse, ser el escultor de su propia vida, por supuesto en vistas a las exigencias de la sociedad de mercado. Así pues, además de la adaptación, lo

\footnotetext{
7. Para una profundización en el capitalismo cognitivo, véanse F. Berardi, La fábrica de la infelicidad: nuevas de trabajo y movimiento global, Traficantes de Sueños, Madrid, 2003 y A. Fumagalli, Bioeconomía y capitalismo cognitivo: hacia un nuevo paradigma de la acumulación, Traficantes de Sueños, Madrid, 2010, 8. C. Laval, P. Dardot, La nueva razón del mundo, Gedisa, Barcelona, 2013.
} 
que se desea es cierta inadaptación e insaciabilidad, cierto prurito que aliente ulteriores transformaciones.

Con esto, además, se consuma definitivamente la ruptura con aquella concepción del capitalismo que retrata a éste en tanto que una suerte de unidad sustancial y hasta cierto punto coherente. El capitalismo, más que una realidad concreta y definida, tiene que ver con un conglomerado de redes por donde transitan relaciones y acciones que se tejen y retejen continuamente por parte de los actores que entran en juego y que se diseminan por las distintas esferas de la sociedad, obviamente en un marco de competencia, asimetría, desigualdad, violencia y explotación. De allí que la lucha contra el capitalismo sea extremadamente compleja y no sea nada fácil hacia dónde apuntar, ya que de algún modo está y no está en todas partes, al tener la capacidad de colarse furtivamente en todos los espacios de la vida.

\section{El capital que tenemos dentro}

Todo lo anterior cristaliza en la producción de nuevas formas de subjetividad donde la vida pasa a ser aprehendida en tanto que potencia o potencialidad, donde ésta se isomorfiza respecto al capital. La vida comparece entonces en tanto que una suerte de capital encarnado, un capital llamado humano, que no por ser difuso deja de ser menos real. El capital se subjetiviza y, por así decirlo, ya no está exclusivamente fuera sino también dentro de nosotros. Entendiéndose como capital humano, el trabajador instaura una relación reflexiva consigo mismo, con las maneras en que administra su existencia, en vistas a una (continua) transformación que lo haga lo más apto posible para alcanzar sus expectativas laborales. El capital humano resulta en un sujeto que actúa sobre sí y que se concibe en proceso o en ruptura, ligado a una identidad precaria, fluida, dúctil y oscilante. Por ello, sea en el ámbito laboral o en el consumo, cuyas fronteras en definitiva se tambalean desde hace tiempo, se alimenta en el fuero interno de los individuos la sensación de carencia o falta, el sentimiento de incompletitud y de insatisfacción, con el fin de activar e intensificar el movimiento. O para motivar a los empleados desde fuera también se promueven desde el management mecanismos de presión o extorsión que siguen el espíritu de la célebre vitality curve de Enron, por la que se predica el despido anual de un porcentaje de trabajadores en aras de aumentar el rendimiento de la empresa.

De lo que se trata es de introyectar los modelos de gestión en cada individuo, de aplicar la revolución permanente sobre cada uno con el propósito de incrementar su valor, y 
por consiguiente su empleabilidad, en el mercado. De allí la proliferación de técnicas de superación personal o de profesiones en boga como el coach y sus múltiples variantes, que conducen al robustecimiento y encauzamiento de las energías de los individuos, a la vocación por sobreponerse airosamente a todas las adversidades. ${ }^{9}$ Eso alcanza su extremo con la resiliencia, aquello que según Boris Cyrulnik nos descubre la maravilla del dolor, ${ }^{10}$ concepto a partir del cual también se aspira a positivizar y rentabilizar la desgracia o el sufrimiento. Como en la imagen del capitalismo de Boltanski y Chiapello, el sujeto contemporáneo debe sobresalir por tener la habilidad de superar los conflictos y convertirlos en un vector de progreso. ${ }^{11}$

La teoría del capital humano no es nueva. Fue teorizada en la década de los años setenta por economistas como Theodore Schultz o Gary Becker y, poco después, examinada por Michel Foucault en El nacimiento de la biopolítica. ${ }^{12}$ Lo que nos interesa es que, mutatis mutandis, comparece como la contracara productiva y capitalista, obviamente desnaturalizada, del cuidado de sí (epimeleia heautou) o la estética de la existencia expuesta por Foucault. En sendos casos se predica un ejercicio de autoconstitución activa, lo que supone una liberación frente a las cadenas de un sujeto fijo o tener la capacidad de hender o erosionar la identidad sólida y salir (ex-sistir) de uno mismo; esto es, se pone en práctica, mediante una constante interrogación crítica, una moderna ascética de autoperfección y autosuperación. ${ }^{13}$ Se trata de incentivar una suerte de inconformismo radical, que suscite la perentoria necesidad de observarse, enmendarse y mejorarse.

En el capital humano, empero, se pone en ejercicio con un telos muy definido y siguiendo patrones heterónomos, marcados por las valoraciones suministradas por el mercado. Pese a que en muchas ocasiones esto se ampara en una retórica de la libertad,

\footnotetext{
9. M. Marzano, Programados para triunfar: nuevo capitalismo, gestión empresarial y vida privada, Tusquets, Barcelona, 2011. 10. B. Cyrulnik, La maravilla del dolor: el sentido de la resiliencia, Granica, Buenos Aires, 2001.

11. No deja de ser contradictorio que, por un lado, se exalte sobremanera y de forma voluntarista la capacidad de autotransformación de los individuos, mientras que por el otro se deniegue la capacidad de transformación del entorno económico, cuyas reglas son presentadas como leyes naturales frente a la cuales no se puede hacer nada ni hay alternativa posible.

12. M. Foucault, El nacimiento de la biopolítica: curso en el Collège de France (1978-1979), Akal, Madrid, 2009. Esta cuestión entronca asimismo con algunas intuiciones anticipadas por Günther Anders, quien en La obsolescencia del hombre destacó que el sujeto contemporáneo se hallaba abocado a un proceso de autometamorfosis. En su opinión, esta transformación constante del hombre se debía llevar a cabo por su afán de complacer a los aparatos y máquinas que la especie humana no cesaba de crear, aunque sus observaciones también pueden ser aplicadas a la lógica del capital, que a fin de cuentas es la que vertebra los procesos que le inquietaban. Según Anders, el hombre aparece como un instrumento que desea y persigue su propia instrumentalización, que se obstina y realiza en ésta. De allí que hable de una deshumanización que, recuérdese, tiene su origen en uno mismo y es efectuada volitivamente, incluso desesperadamente. Su concepto de vergüenza prometeica, desarrollado en relación con el universo maquínico que nos rodea, podría ser reformulado para nuestros fines como una suerte de vergüenza ante las demandas del capital. G. Anders, La obsolescencia del hombre, Pre-Textos, Valencia, 2011. 13. Eva Illouz ha diseccionado este proceso a través del ethos terapeútico, el cual conduciría a lo que llama el capitalismo emocional. Véanse E. Illouz, Intimidades congeladas: las emociones en el capitalismo, Katz, Buenos Aires, 2007 y La salvación del alma moderna: terapia, emociones y la cultura de la autoayuda, Katz, Madrid, 2010.
} 
de facto se trata como máximo del espejismo de una libertad irreconocible o paródica: situada, inocua e insustancial. De una libertad confundida con cierta capacidad de elección, por lo general intrascendente, y menoscabada por un lacerante contexto de incertidumbre, competencia, stress, ansiedad, sufrimiento y violencia. ${ }^{14}$ La liberación de las cadenas de la identidad del sujeto, su desfijación o desujeción, no se efectúa en el capital humano bajo la estela de unas prácticas de libertad, pues se nos exige un tipo de transformación determinado, en especial cuando, como es frecuente, uno se encuentra preso en el endeudamiento. ${ }^{15}$ Este capitalismo, por decirlo sumariamente, no se afirma en el ser sino en el devenir, en una suerte de obstinada expropiación, desrealización y desreificación, forzando a sus integrantes a participar de ese mismo devenir que impulsa. Allí se descubre la impotencia de la potencia promovida.

Eso concuerda a su vez con el clima de precarización establecido, tanto por lo que se refiere a la precariedad existencial (precariousness) como la laboral (precarity); en definitiva, ambas caras se amalgaman y complementan. Como ha denunciado Guy Standing, uno de los problemas de este colectivo, frecuentemente llamado precariado, es que es una clase social sin conciencia de clase, de una clase en sí pero no para sí, entre otros factores por encontrarse en competencia o en guerra consigo misma. ${ }^{16}$ Nos referimos a un colectivo que, abismado en la incertidumbre y la inestabilidad crónica de sus empleos y subempleos mal pagados, acusa a sus otros miembros de su vulnerabilidad e indignidad, en especial a grupos poco bienvenidos como los inmigrantes. De este modo, no se fomenta la unión sino la desunión, no se genera acción común sino rivalidad, lo que incrementa, agrava y enquista el clima de competencia.

La precarización laboral se explica por la consolidación de la crisis del empleo, anunciada fútilmente desde hace largo tiempo. ${ }^{17}$ La respuesta paradójica a esta crisis, y sin embargo muy lógica a la vez, reside en un giro perverso por el que todos devenimos empleados, aunque sea de nosotros mismos, bajo esa denominación de empresario de sí mismo. ${ }^{18}$ En el momento en que el mercado no puede garantizar el trabajo remunerado, cuando el endémico desempleo estructural no cesa de incrementar, es también cuando mágicamente cualquier persona recibe el estatuto de trabajador (mientras se consuma la tendencia a la desempresarización del empleo). El problema del paro ya no alude tanto

\footnotetext{
14. Slavoj Žižek ha escrito al respecto: “La libertad de decisión del sujeto de la 'sociedad del riesgo' no es la libertad de quien puede elegir su destino, sino la libertad ansiógena de quien se ve constantemente forzado a tomar decisiones sin conocer sus posibles consecuencias”, S. Žižek, En defensa de la intolerancia, Diario Público, Barcelona, 2010, p. 75-76.

15. M. Lazzarato, La fábrica del hombre endeudado: ensayo sobre la condición neoliberal, Amorrortu, Madrid, 2013.

16. G. Standing, Precariado: una nueva clase social, Pasado y Presente, Barcelona, 2013.

17. Por ejemplo, J. Rifkin, El fin del trabajo: nuevas tecnologías contra puestos de trabajo, Paidós, Barcelona, 2001.

18. J. Moruno, La fábrica del emprendedor: trabajo y política en la empresa mundo, Akal, Madrid, 2015.
} 
a un problema de la sociedad como individual, del que uno debe responsabilizarse y hacerse cargo, frente al cual debe hallar una solución. De ahí la eclosión de una figura laboral como los autónomos, el ejemplo más depurado del empresario de sí mismo y simultáneamente, en muchos sentidos, el nuevo rostro del proletariado. De este modo, la teoría del emprendedor, postulada por Schumpeter, antes restringida a una minoría aristocrática y heroica, se proyecta como el ethos requerido al conjunto de trabajadores. No deben sorprender, por eso, los sistemáticos intentos de empresarializar la universidad o de introducir clases de ética empresarial en la educación secundaria.

El sujeto debe ser por fuerza, por necesidad, un sujeto emprendedor. Como se dice pomposamente, cada uno pasa a ser el jefe de sí mismo. El capital, lo hemos indicado, no se halla solamente fuera sino dentro de nosotros. De ahí que la explotación pase a ser autoexplotación, la cual puede ser mucho más feroz e inclemente que la primera. Además, esto deriva en una desresponsabilización del mercado por su incapacidad a la hora de acoger y retribuir todo el trabajo que se realiza en su seno: la empresa tradicional deja de ser el necesario acceso al mercado laboral porque potencialmente cada uno de nosotros es una empresa. La crisis contemporánea del empleo, el periodo en que éste es más difícil de obtener bajo unas condiciones honrosas, conduce paradójicamente a que todos seamos trabajadores y responsables de nuestra inactividad laboral. El sentido original del paro queda adulterado, porque si uno no trabaja es porque "no quiere" o "no hace lo suficiente". El problema real es que el desafío contemporáneo no es tanto trabajar como conseguir un sueldo digno en un escenario donde el capitalismo cognitivo se nutre sin cesar de los inestimables productos y beneficios del trabajo gratuito. Hoy en día, se constata como nunca, y de manera dramática, la diferencia existente entre trabajo y empleo (es decir, el trabajo remunerado). ${ }^{19}$

Una vez que nos asumimos, conducimos y administramos como capital, las diferentes facetas de la vida aparecen señalizadas o interiorizadas como posibles inversiones u oportunidades. La realidad que nos circunda, sean trabajos, títulos, propiedades o contactos, adquiere un aspecto potencial: no solamente cuenta qué es sino en qué se puede convertir, qué réditos puede brindar. No por casualidad se habla sin cesar de expresiones como capital social, simbólico, cultural o emocional. No se trata, por supuesto, de algo estrictamente novedoso, pero sí de una actitud que se propaga y deviene cotidiana, incluso aceptable o "natural" a los ojos de la sociedad, en absoluto reprochable. El imaginario economicista se expande por las esferas de la existencia y se plasma

19. A. Gorz, La metamorfosis del trabajo: búsqueda del sentido: crítica de la razón económica, Sistema, Madrid, 1997. 
en el vocabulario del día a día. El capital invade la vida entera. En la actualidad, si bien es preciso subrayar que lógicamente esto no es un rasgo privativo del presente, todos los aspectos de la vida son susceptibles de ser considerados como parte del capital en el que nos hemos convertido. También el ocio, y aquellos períodos en los que uno está en paro, pueden transformarse en una inversión de futuro y ambos lapsos de tiempo deben ser racionalizados, léase optimizados. Esta operación consistiría, de algún modo, en desvincular el ocio, un momento necesario en nuestras vidas, de la ociosidad, una actitud deplorable. ${ }^{20}$ El capital se ha convertido en una realidad con aspiraciones totalizantes; según algunos, totalitarias.

Este proceso, además, aparece como una suerte de democratización. Al nivel de los hechos, el motor del capitalismo se identifica cada vez menos con un determinado y minoritario colectivo capitalista o empresario. Las reglas y la cosmovisión del capitalismo se incorporan (en el sentido más pleno de la palabra) en las personas de a pie. Por añadidura, no lo hacen a partir de aquello en lo que estos sujetos puedan pensar (es irrelevante que, por ejemplo, puedan declararse como anticapitalistas o a favor de una corriente como el decrecimiento) porque lo determinante son las elecciones y decisiones que tienen que ver con el trabajo y el consumo cotidiano, con el referéndum diario del mercado. Dicho de otro modo, las dinámicas que se prodigan pueden pasar por la consciencia, pero procurando eludir el dictado de la conciencia. De hecho, la promoción de formas de consumo y ocio anticapitalistas no solamente expande, a nivel fáctico, el espacio del capital sino que, además de neutralizar energías anticapitalistas, contribuye asimismo a la legitimación del sistema al que critican, al poner de relieve su tolerancia o pluralismo a nivel de pensamiento.

El problema de la ideología, por eso, no debe ser enfocado sólo como una falsa conciencia o ilusión que enmascara o transfigura (léase edulcora, naturaliza y legitima) la apariencia de la realidad circundante. El problema no es principalmente que los individuos "no saben lo que hacen". Aquel temor de Henry Ford o aquella esperanza de Rosa Luxemburg, según los cuales el capitalismo se desmoronaría en seguida si los trabajadores llegaran a enterarse de las injusticias y violencias escondidas detrás del capital, deja de tener sentido. Una buena parte de la población se sabe explotada, sin que eso anime la lucha social. Por ello conviene reivindicar una concepción de la ideología como la desarrollada por Peter Sloterdijk ${ }^{21}$ y Slavoj Žižek, ${ }^{22}$ la cual se aleja del intelectualismo

20. Una de las exposiciones más interesantes y radicales de esta nueva ética de la productividad es la del laureado economista James M. Buchanan. Véase J.M. Buchanan, Ética y progreso económico, Ariel, Barcelona, 1996.

21. P. Sloterdijk, Crítica de la razón cínica, Siruela, Madrid, 2003.

22. S. Žižek, El sublime objeto de la ideología, Siglo XXI, México D.F., 1992. 
moral y del cognitivismo, acercándola en cambio a la cuestión del cinismo: simplificando, las personas en realidad sí que "saben" a grandes rasgos lo que hay, en muchos casos incluso lo lamentan o lo tildan de injusto o indeseable, pero eso no altera su conducta de manera significativa. El conocimiento de la verdad, si bien no es inútil o inofensivo, tampoco es intrínsecamente transformador o revolucionario. El problema se dirige, por lo tanto, a la conexión o desconexión entre saber y praxis. Aquello que importa en la ideología en el seno del capitalismo no es ante todo, aunque no dejan de ser importantes, ni el elemento discurso ni el afectivo, sino el de orden pragmático.

Además, debido a esta "democratización" se nos responsabiliza y hace cómplices a nivel fáctico de nuestros males y desgracias. Esta responsabilización tiene por lo pronto una doble cara. Primero, concierne a las injusticias que continuamente se perpetran, en la medida en que todos formamos parte del engranaje del capital; como se suele decir, allí donde todos son culpables nadie lo es. Asimismo, se nos responsabiliza individualmente de nuestros fracasos particulares. Aquí es donde los efectos de las retóricas del pensamiento positivo salen a escena. En la medida en que el sujeto es una potencialidad más que una realidad, cada uno es el responsable último de no conseguir lo que desea y la autosuperación se convierte en un inexcusable imperativo categórico. Así se desprende de sentencias de best-sellers como "sólo tú puedes mejorar tu suerte y hacerte feliz a ti mismo" (Wayne Dyer, Tus zonas erróneas) o "aquello en lo que piensas es lo que atraes. Toda tu vida es una manifestación de los pensamientos que te pasan por la mente" (Rhonda Byrne, El secreto). ${ }^{23}$ Así, los problemas no se explican tanto por el entorno como por la incapacidad de encararlos adecuadamente y sobrevivir dentro de él. En tales casos, no es que se haya fallado sino que pasamos a ser personas fracasadas o losers. ${ }^{24}$

En la medida en que nos entendemos y desenvolvemos en tanto que capital humano, podríamos hablar asimismo de una suerte de autoalienación; una alienación a menudo no reconocida o catalogada como tal, al estar propulsada o ser puesta en práctica por uno mismo. Uno no solamente padece la alienación, además la promueve y alimenta, la

\footnotetext{
23. Para una introducción a las narrativas de la autoayuda véase D. Viñas, Erótica de la autoayuda: estrategias narrativas para promesas terapéuticas, Ariel, Barcelona, 2012.

24. No deja de ser espeluznante cómo esta lógica se puede proyectar incluso a las personas aquejadas de cáncer. Según este modo de pensar, se podría culpabilizar a alguien por el mero hecho de fallecer a causa de esta enfermedad, al sostener que la salud depende exclusivamente de la actitud de cada uno. Su muerte certificaría así su fracaso vital y podría llegar a ser, más que un motivo de duelo, uno de vergüenza. Véase B. Ehrenreich, Sonríe o muere: la trampa del pensamiento positivo, Turner, Madrid, 2011. Asimismo, es preciso recordar que esta manera de pensar ha influido en el desarrollo de las nuevas formas de subjetividad en tanto que lubricante intelectual que mitiga y desautoriza los actos de resistencia, algo en lo que Christian Laval y Pierre Dardot, más centrados en elementos como el origen deportivo de esta mentalidad, no profundizan en La nueva razón del mundo. La hiperresponsabilización del individuo conduce, claro está, a la exculpación de los factores externos y al mantenimiento del orden vigente.
} 
desea incluso, obviamente en un contexto que nos impele o fuerza a ello. Así se evidencia la eficacia de lo que Nikolas Rose ha llamado el actual gobierno a través de la libertad (government through freedom). ${ }^{25}$ En el mismo sentido, Dardot y Laval señalan con acierto que "las nuevas técnicas de 'empresa de sî' alcanzan sin duda el colmo de la alienación al pretender suprimir todo sentimiento de alienación”. ${ }^{26}$ En efecto, la consolidación de estas actitudes conduce a que no sean vistas como conflictivas sino naturales. Al parecer, el mercado brinda la imagen vívida de la libertad y se convierte en el paradigma de ésta.

\section{De la masa al prosumidor}

Este proceso de "democratización" del capitalismo resulta también visible en el terreno de la innovación, que progresivamente se confía menos a una minoría experta y especializada. En cierto modo, y de manera deliberadamente provocativa, se puede hablar por eso de un capitalismo de la confianza; esto es, un capitalismo fundado en la confianza que profesa hacia las acciones (y no las intenciones) de las personas de a pie, incluyendo a sus detractores. Se confía en que cada ruptura o amenaza puede ser domesticada, recontextualizada y resignificada. De ahí, por ejemplo, que una práctica concebida con fines emancipatorios como el empowerment, se haya convertido en breve en una de las manidas referencias empresariales del presente. Un discurso como el de la autonomía también ha podido ser adoptado y enarbolado por el capitalismo cognitivo.

El auge de este capitalismo cognitivo coincide con una reconsideración práctica de la población que se aparta de la tradicional idea de masa, por lo menos dentro de la esfera económica. Aunque sea sucintamente, conviene recordar que bajo su interpretación clásica, desde los escritos decimonónicos de Gustave Le Bon, ${ }^{27}$ la masa era retratada como un colectivo informe, homogéneo, irracional y volátil. Por su estupidez, carecería propiamente de logos, de una voz digna de ser escuchada y tener en cuenta. Por su volubilidad, sería poco de fiar y potencialmente violenta, además de intolerante. La masa era presentada como un sujeto político próximo a la barbarie, incompatible con una política y una democracia merecedoras de tal nombre. La masa, siguiendo los términos de Rancière, era la parte de los que no tienen parte. ${ }^{28}$

25. N. Rose, Governing the soul: the shaping of the private self, Routledge, London, 1991.

26. C. Laval, P. Dardot, La nueva razón del mundo, p. 332.

27. G. Le Bon, Psychologie des foules, PUF, Paris, 1991.

28. J. Rancière, El desacuerdo: política y filosofía, Nueva Visión, Buenos Aires, 1996. 
Como se sabe, frente a la masa se ha reivindicado en los últimos lustros el concepto de multitud, sobre todo a raíz de acontecimientos como el Global Action Day de Seattle, en 1999, o de nuevo con las revueltas árabes e indignadas de $2011 .{ }^{29} \mathrm{~A}$ nivel histórico, la multitud fue asimismo el heterogéneo sujeto político sobre el que se construyó y desarrolló Internet. Según la definición clásica, la multitud sobresale por fragmentar la identidad de la masa y vertebrarse sobre la singularidad de sus participantes. Su regla es la de la unión en la diferencia, la construcción en común y en colaboración, tratando de eludir la subordinación a cualquier tipo de identidad fija o el gobierno de la soberanía. Por eso, la multitud es intrínsecamente irrepresentable y adopta formas de funcionamiento reticulares que predican una inclusividad absoluta y una hospitalidad hacia la diferencia. En realidad, el ser de la multitud es el devenir, una apertura perenne que no se deja sojuzgar o maniatar por el pasado y que no consiente en ser encapsulada dentro de unos conceptos, ideologías o identidades en concreto. ${ }^{30}$

La multitud puede convertirse en el futuro sujeto político de la emancipación pero, en cualquier caso, cabe tener en cuenta que también lo es ya el del capitalismo del presente. Ahora sí que se les reconoce y solicita un logos a muchos trabajadores, quienes son considerados, al menos en un marco determinado, como dignos de ser escuchados y tenidos en cuenta; a quienes incluso se les concede (por necesidad) determinada capacidad de decisión. En este sentido, las observaciones de Paolo Virno, quien ha destacado en todo momento la ambivalencia de la multitud, ${ }^{31}$ han sido más prudentes que las de Antonio Negri o Michael Hardt. De hecho, el management de los últimos tiempos ha reivindicado la importancia de la estructura reticular o del factor humano como un componente esencial para el buen desarrollo de la empresa, valorando y promoviendo las facultades intelectuales o la capacidad de aprendizaje de sus trabajadores "cualificados". El empleado ideal del presente debe ser proactivo, comprometido, propositivo, resolutivo, polivalente, autónomo; en suma, un buen emprendedor.

Algo semejante ocurre en la esfera del consumo, lo que de rebote ha contribuido a la precarización del empleo. El consumo ya no es visto como la última fase o el simple destinatario del proceso de producción, allí donde se cierra su círculo. Se ha descubierto que no es enteramente pasivo y que, lejos de ser estéril, detenta un estimable potencial productivo e incluso creativo. Detrás del consumo, se esconden múltiples formas de

\footnotetext{
29. En otro lado hemos diseccionado el concepto de multitud y sus ambivalencias. Véase E. Straehle, "Las dificultades de la multitud: discusión con Negri y Hardt”, en Oxímora. Revista Internacional de Ética y Política, 2, 2013, pp. 39-57.

30. Véanse T. Negri, M. Hardt, Multitud: guerra y democracia en la era del Imperio, DeBolsillo, Barcelona, 2006 y P. Virno, Gramática de la multitud: para un análisis de las formas de vida contemporáneas, Traficantes de Sueños, Madrid, 2003.

31. P. Virno, Ambivalencia de la multitud: entre la innovación y la negatividad, Tinta Limón, Buenos Aires, 2011.
} 
trabajo y producción, que se pueden convertir en capital. De allí el justificado éxito de la etiqueta de prosumer o prosumidor, acuñada por Alvin Toffler, ${ }^{32}$ que da cuenta de un escenario en donde se desdibujan las fronteras entre el productor y del consumidor. La producción no se encuentra solamente, y en algunos casos tampoco de manera mayoritaria, en el dominio de los trabajadores. A fin de cuentas, podemos entender el capital humano desde la misma gramática del prosumidor, donde consumir y producir la vida son fenómenos que interseccionan y se confunden.

A pesar de que hablar de la capacidad productiva de los consumidores no sea en rigor una novedad, gracias a un universo como Internet ha podido ser observado con mayor facilidad, donde se ha dado una democratización de los medios de producción ${ }^{33}$ o el paso a una economía de la atención. Conviene precisar que en Internet se asiste al advenimiento de un mundo extraño a los parámetros de la economía clásica. No sólo ha favorecido la multiplicación del trabajo gratuito, también ha implantado múltiples formas de consumo gratuito. ${ }^{34}$ La economía de la atención se nutre principalmente de transacciones derivadas del acto de consumo, como intercalar o añadir publicidad contextual, pero que en sentido estricto no se encuentran dentro de ese mismo acto. En la actualidad, acciones cotidianas como contemplar un video en YouTube, leer el post de un $b \log$, mirar un catálogo de productos cualquiera o consultar el propio correo electrónico suelen constituir una acción económica y un acto de consumo. Ahí también se percibe la omnipresencia del capital: estamos rodeados e involucrados en una infinidad de actos económicos que no se exhiben como tal y que forman parte de nuestra rutina diaria.

La capacidad económica y productiva de los usuarios en Internet comenzó a despuntar a raíz de la irrupción de la web 2.0, que rompió con la unilateralidad casi absoluta entre productores y consumidores al proporcionar páginas web para uso personal. Desde entonces, los usuarios comenzaron a desempeñar un rol cada vez más destacado en la expansión de Internet, como se constató con la emergencia de la blogosfera y otro tipo de páginas personales o con la multiplicación de redes sociales de toda índole. Asimismo, se popularizaron otras que se basaban en la cooperación descentralizada y espontánea de sus usuarios. ${ }^{35}$ El eslogan de Indymedia -don't hate the media, become the media- puede ser visto como el epítome de esta actitud. Los modelos

32. A. Toffler, La tercera ola, Plaza \& Janes, Barcelona, 1981, p. 282-283.

33. C. Anderson, Makers: the new industrial revolution, Random House, London, 2013.

34. C. Anderson, Gratis: el futuro de un precio radical, Tendencias Editores, Barcelona, 2009.

35. Véase S. Johnson, Sistemas emergentes: o qué tienen en común hormigas, neuronas, ciudades y software, Turner, Madrid, 2003. 
más reivindicados fueron Wikipedia y Linux, pero también triunfaron iniciativas privadas donde la gran mayoría de los contenidos han sido producidos y subidos por los usuarios. Cabe añadir que Mark Zuckerberg advirtió con prontitud la magnitud de este fenómeno y Facebook confió directamente a su comunidad digital la traducción de su web a los distintos idiomas o el desarrollo de las futuras aplicaciones. ${ }^{36}$ Algo parecido se podría comentar de Google, empresa que ha sabido rentabilizar la colaboración desinteresada de sus usuarios. Por no hablar de que Linux devino el soporte gratuito empleado o aprovechado por un buen número de corporaciones privadas, incluyendo a IBM. De ahí la reivindicación de prácticas basadas en el brainstorming, la sabiduría de la multitud o la inteligencia colectiva, las cuales serían más eficientes que los modelos fundados en el criterio de expertos. ${ }^{37}$

Por todo lo anterior, en los últimos tiempos se ha concedido una mayor atención al campo del consumo y a su reverso productivo. En este sentido, Eric von Hippel ha resaltado el rol desempeñado por los usuarios en la innovación, razón por la que ha abogado por una democratización de ésta y el cultivo de comunidades de creación, tales como las que ejemplarmente se han organizado en movimientos como el free software o el open source y que sirven de referencia para las entidades empresariales. ${ }^{38}$ Por eso, Hippel también se posiciona en contra de las patentes o del derecho de propiedad intelectual, por obstaculizar el desarrollo de la innovación. Sin embargo, en su caso como en el de otras ilustres personalidades asociadas al commons, entre los cuales sobresale el randiano Jimmy Wales, fundador de Wikipedia, esta crítica a la propiedad intelectual y la defensa del común no se hace en contra sino precisamente a favor del capitalismo, de uno que suprima las intervenciones y trabas que lesionan o entorpecen la libertad del mercado.

Todo eso ayuda a explicar la consolidación de este capitalismo de la confianza mencionado antes, lo que obviamente no debe tapar ni hacer olvidar el reverso policial que se esconde detrás de estos emporios o que la neutralidad de la red no deja de ser una ficción, por no hablar de las resoluciones tomadas periódicamente por los gobiernos de cada país. Se ha descubierto en el consumo una fuente de extracción sin par de trabajo gratuito, en muchos casos voluntaria y “altruista”, de modo que esta dimensión es introducida de diversas maneras dentro de la cadena de producción y se pone en práctica una

36. J. Jarvis, Y Google ¿cómo lo haría?, Gestión 2000, Barcelona, 2010, p. 53.

37. Véanse S. Johnson, Las buenas ideas: una historia natural de la innovación, Turner, Madrid, 2011; J. Surowiecki, Cien mejor que uno: la sabiduría de la multitud o por qué la mayoría siempre es más inteligente que la minoría, Tendencias, Madrid, 2005; D. Tapscott y A. Williams, Wikinomics: la nueva economía de las multitudes inteligentes, Paidós, Barcelona, 2007. 38. E. von Hippel, Democratizing Innovation, MIT Press, Cambridge, 2005. 
suerte de cínica e ingrata economía del don. A menudo, esta colaboración se restringe a la aportación de contenidos, de modo que muchas páginas de servicios, incluyendo Facebook, Google o YouTube, a fin de cuentas son poco más que intermediarias de los usuarios, lo que sin embargo les hace tener que adaptarse considerablemente a los deseos, requerimientos e iniciativas de éstos. ${ }^{39}$ Por añadidura, estos mismos usuarios pueden ser asimismo los motores de innovación que ayudan a la mejora de los servicios o a diversos aspectos del producto. En este contexto, cabe recordar la importancia del crowdsourcing no tanto por su incidencia real en la economía del presente como por brindar un posible ejemplo anticipado de la economía que nos espera.

Como hemos visto, los modelos de economía basados en el común, así como otros tipos de iniciativas, pueden ser integrados lucrativamente y en definitiva privatizados en el seno del capitalismo, como se podía colegir según la exposición realizada por Boltanski y Chiapello. Eso conlleva a su vez el tránsito a la tercera figura mencionada al principio, pues lo que se integra entonces es la capacidad productiva de un sujeto valorado por su potencialidad, un potencial de innovación o de ruptura a fin de cuentas imprevisible. Es decir, ya no se trata de que el capitalismo se renueve en virtud de la domesticación de ese afuera, sino que en buena medida este gesto de apropiación o territorialización ni siquiera es necesario. Continuamente, el mismo afuera emprende acciones y genera productos que pueden ser capturados, parasitados y capitalizados.

39. Al fin y al cabo, la libertad otorgada al prosumidor también puede favorecer la organización de actos de protesta, resistencia o subversión. Las necesidades del mercado fuerzan a que incluso páginas de contenidos como Facebook o YouTube deban conceder un siempre ambivalente margen de maniobra a sus usuarios, con frecuencia a desgana. En este sentido, la red puede convertirse sin dificultad en un espacio de contrainformación, contraeconomía y contrapoder. A nivel ideal, los prosumidores detentan un poder del que por lo general no son verdaderamente conscientes, un poder que se puede cultivar, articular y potenciar. 